\title{
MENCERMATI ARAH PENDIDIKAN INDONESIA
}

Oleh : Sri Mujiarti Ulfah.S.Sos. M.AP

\section{Pengantar}

Pendidikan bukan lagi untuk semua orang, namun kini telah mengarah hanya untuk sekelompok orang yang memiliki — kantong teball. Adagiom yang mengatakan _orang miskin dilarang sekolah` juga menjadi jargon yang sering kita dengar dan semakin nyaring ketika memasuki tahun ajaran baru.

Masuk ke perguruan tinggi pun seakan menjadi mimpi bagi banyak orang, bahkan tak jarang kita temukan fakta mahasiswa karena keterbatasan biaya terpaksa harus berhenti kuliah. Bahkan yang paling memprihatinkan bagaimana cerita sedih si anak pintar, dengan hati berbunga-bunga karena telah dinyatakan lulus seleksi di perguruan tinggi bergengsi di Indonesia dia melakukan daftar ulang namun apa mau dikata pihak perguruan tinggi bergengsi tersebut meminta uang untuk biaya gedung, sedangkan si anak pintar tadi bersama ibunya tidak memiliki uang sebesar itu, pada akhirnya semua keinginanya untuk kuliah diperguruan tinggi bergengsi di Indonesia itupun pudar. Ironis memang.

Sekelumit cerita diatas belum menggambarkan bagaimana output pendidikan bangsa ini. Kita berbangga hati ketika ada sebagian generasi kita memiliki prestasi baik dibidang saints, tekhnologi, dll, atau kalau standarnya adalah banyaknya medali olimpiada ilmiah yang kita raih maka kita tetap berbangga. Namun, semua itu jauh lebih sedikit dibangding bagaimana gambaran generasi kita saat ini. Sek bebas, narkoba, mabuk-mabukan, tawuran, berani dengan orang tua, atau ketika dia bekerja perilaku korupsi dan suap menyuap menjadi hal yang biasa. semua hal itu menambah miris hati kita, akan kita bawa kemana bangsa ini dengan kondisi generasi yang untuk menentukan masa depannya pun dia tidak mampu? Namun pertanyaan lebih keras tertuju kepada pemeritah sebagai pihak yang memiliki otoritas dalam memegang kendali pendidikan, kemana arah pendidikan indonesia?

Tulisan ini akan mencoba menganalisis untuk menjawab kemana arah pendidikan Indonesia. Komodifikasi pendidikan

Gambaran dunia pendidikan kita saat ini sungguh menyedihkan, sebagaimana dituturkan oleh Hanif Saha Ghafur, pengajar UI yang juga penasihat Menteri Pendidikan Nasional (Special 
Advisor for the Minister), mengatakan bahwa akses masyarakat terhadap perguruan tinggi rendah. Pada 2010, hanya 17\% yang diterima masuk PTN. Selebihnya, kelas menengah-atas. Tragisnya, persentase itu terus turun menjadi $15 \%-16 \%{ }^{1}$. Lebih ironis lagi apa yang di gambarkan oleh Darmaningtyas, pakar pendidikan dari Perguruan Tinggi Taman Siswa Yogyakarta, malah melihat kondisi sesungguhnya jauh lebih parah. Menurutnya, jumlah golongan miskin di PTN dan perguruan tinggi badan hukum milik negara (PT BHMN) tahun 2010 tinggal 4\% saja ${ }^{2}$.

Rendahnya akses masyarakat untuk melanjutkan pada jenjang lebih tinggi lebih disebabkan karena biaya pendidikan yang tidak terjangkau. Tak dapat dipungkiri bahwa konsep privatisasi PT BHMN merupakan penyebab mahalnya pendidikan di negara kita ${ }^{3}$.

Berubahnya manajemen perguruan tinggi menjadi otonomi berawal dari dikeluarkannya Peraturan Pemerintah No. 61 tahun 1999 Tentang Penetapan Perguruan Tinggi Negeri sebagai Badan Hukum. Pada tahun 2000 pemerintah menetapkan status BHMN pada empat PTN yang dipandang siap yaitu Universitas Indonesia dengan PP No. 152/2000. Universitas Gadjah Mada PP.No. 153/2000. IPB menjadi BHMN dengan dikeluarannya PP No.154/2000. Menyusul ITB dengan PP. No. 155/2000 menjadi BHMN. Beberapa tahun kemudian menyusul Universitas Sumatera Utara menjadi BHMN dengan PP.No.56/2003. Universitas Pendidikan indonesia menjadi BHMN dengan PP.No 6 tahun2004. Dan UNAIR menjadi BHMN dengan PP.No.30 tahun 2006.

Kemudian, tanggal 17 Desember 2008, melalui jalan yang cukup panjang, yang diwarnai pro dan kontra, DPR RI tetap mensahkan UU No. 9 Tahun 2009 tentang Badan Hukum Pendidikan (UU BHP). Keberadaan pihak yang pro dan kontra terhadap pengesahan UU BHP karena di satu sisi kehadiran UU BHP dianggap merupakan pencerahan bagi dunia pendidikan, sekaligus dijadikan sebagai payung hukum bagi penyelenggaraan pendidikan formal di Indonesia. Namun, di sisi lain justru kehadiran UU BHP dianggap sebagai bentuk kapitalisasi dunia pendidikan, yang berdampak pada liberalisasi penyelenggaraan pendidikan, dan sebagai jalan lepas tangannya pemerintah terhadap dunia pendidikan sedikit demi sedikit.

\footnotetext{
${ }^{1}$ Sudarmadi. Menata Ulang Manajemen Perguruan Tinggi. 2011

${ }^{2}$ ibid

${ }^{3}$ ibid
} 
Konsekuensi Perguruan Tinggi BHMN menyebabkan mahalnya biaya pendidikan tinggi sehingga semakin tidak terjangkau oleh masyarakat berpenghasilan rendah. Kondisi ini berlanjut dengan diajukannya tuntutan judicial review terhadap UU BHP ke Mahkamah Konstitusi oleh sekelompok masyarakat. Hasil judicial review dalam Amar Putusan Mahkamah Konstitusi RI No. 11-14-21-126-136/PUU-VII/2009 dinyatakan bahwa UU BHP tidak mempunyai kekuatan hukum yang mengikat. Alasan yan diberikan MK adalah bahwa UU BHP bertentangan dengan UUD 1945 yang mengamanatkan agar pemerintah dapat menyelenggarakan pendidikan untuk seluruh masyarakat, pertama karena secara yuridis UU BHP tidak sejalan dengan UU lainnya dan subtansi yang saling bertabrakan, kedua UU BHP tidak memberikan dampak apapun terhadap peningkatan kualitas peserta didik dan ketiga_UU BHP melakukan penyeragaman terhadap nilai-nilai kebhinekaan yang dimiliki oleh badan hukum pendidikan yang telah berdiri lama di Indonesia, seperti yayasan, perkumpulan, badan wakaf dan lain-lain.

Lahirnya UU BHP merupakan bagian dari amanat UU Sisdiknas Nomor 20 Tahun 2003, hal ini dikemukakan pada Pasal 53 UU Sisdiknas yang memerintahkan agar penyelenggara dan/atau satuan pendidikan formal yang didirikan oleh pemerintah atau masyarakat berbentuk badan hukum pendidikan. Sehubungan dengan itu, Pasal 53 Ayat (4) UU Sisdiknas memerintahkan agar ketentuan tentang badan hukum pendidikan ditetapkan dengan undang-undang tersendiri. UU BHP yang telah disahkan merupakan sebuah konsep yang sudah 36 kali direvisi dimulai sejak tahun 2003 dan baru di jadikan UU setelah 36 kali revisi di tahun $2008 .^{4}$

Menurut Prof. Dr. Jimly Asshiddiqie, — penerapan BHMN sama dengan gejala kapitalis pendidkan yang memberatkan mahasiswa dan stakeholder\|. ${ }^{5}$ Sedangkan menurut Darmaningtyas, pengurus Majelis Luhur Tamansiswa Yogyakarta, mengatakan -Karena diprivatisasi dalam bentuk PT BHMN, mereka lalu ingin cari untung karena berpikir bantuan pemerintah sewaktu-waktu dapat distop. BHMN berpikir cari dana abadi sehingga bayarnya mahal,॥. Menurut Ichlasul Amal, guru besar di UGM, Perubahan besar terjadi setelah beberapa lembaga pendidikan menyandang status BHMN mulai 2003. Status ini membuat manajemen

\footnotetext{
${ }^{4}$ Aryos Nivada.potensi bahaya laten UU BHP. http://www.achehpress.com/2009. diakses tgl 31 januari 2012

${ }^{5}$ Edwin Tirani. Kelola Uang Di Universitas Idealnya BLU http://www.media-indonesia.com/Rabu, 28/3/ 2007. Diaksestgl $1 / 2 / 2012$
} 
lembaga PT harus kreatif menggali dana dari calon mahasiswa berhubung pasokan dari pemerintah terhitung minim. Apalagi, dengan status BHMN mereka diberi keleluasan melakukan seleksi mahasiswa sendiri. Tak mengherankan, manajemen PT pun kemudian membuat kebijakan menyaring mahasiswa plus-plus: pintar secara akademis dan mampu di sisi finansial.

-Kesalahan berada di pihak pemerintah yang menerapkan kebijakan BHMN, bukan pada PTnya, ${ }^{6}{ }^{6}$

Di banyak PTN, untuk masuk fakultas kedokteran tetap harus membayar uang pangkal di atas Rp 100 juta dan untuk jurusan ekonomi-bisnis sekitar Rp 50 juta. - Itu membuat masyarakat bingung karena seleksinya bersama tapi uang masuknya berbeda-beda, tergantung tingkat penghasilan orang tua. Apa bedanya dengan masuk ujian mandiri?॥ ujar Darmaningtyas.

Harus diakui, kebijakan BHMN di tahun-tahun lalu telah membawa dampak komersialisasi PTN dalam skala massif. Betapa tidak, memang awalnya hanya beberapa perguruan tinggi yang menentukan uang pangkal dan biaya kuliah dengan nilai tinggi. Namun, tanpa disadari para pembuat kebijakan, apa yang dilakukan sejumlah BHMN diam-diam telah menciptakan standar pasar baru yang kemudian diikuti perguruan tinggi lain, baik yang negeri maupun swasta.

Tentu ini sebuah ironi. Betapapun akses pendidikan tinggi harus diperluas karena merupakan pilar kemajuan bangsa ke depan. Bila komersialisasi pendidikan terus berlangsung dan warga miskin makin terpinggirkan, Indonesia diprediksi akan kehilangan SDM unggul dalam jumlah besar di masa depan. Kondisi yang tragis mengingat akses pendidikan tinggi di Indonesia masih rendah. Dari 237 juta penduduk RI, baru 5,2 juta orang yang mampu kuliah.

Memang tak tidak dapat dipungkiri bahwa untuk biaya operasional pengelolaan pendidikan mahal, ditambah dengan riset yang harus dilakukan. Menurut Rektor Universitas Negeri Yogyakarta Rohmat Wahab, biaya operasional pendidikan untuk mahasiswa prodi IPS berkisar 22 juta per tahun dan untuk prodi IPA 26 juta-28 juta per tahun (Kompas, 11/7)

Memang anggaran untuk fungsi pendidikan sudah mencapai 20\% dari APBN yang tahun ini sebesar 248 triliun (20,2 \% APBN). Dari jumlah itu, 158 triliun (60\%) ditransfer ke daerah. Hanya 89 triliun yang dikelola pemerintah pusat yang disebar untuk 18 kementerian/lembaga.

\footnotetext{
${ }^{6}$ Rachmanto Aris D. Menata ulang manajemen perguruan tinggi/http://swa.co.id/2011/10/ diakses tgl 31/1/2012
} 
Yang dikelola Kemdiknas sendiri hanya 55 triliun yang dibagi untuk program pendidikan dasar 12,7 triliun (23\%), pendidikan menengah 5 triliun (9,1\%), dan pendidikan tinggi 28,8 triliun (51,9\%). Anggaran Dikti (pendidikan tinggi) itu termasuk di dalamnya PNBP (penerimaan negara bukan pajak), sehingga terlihat sangat besar. Dan semua jumlah itu sebagian besarnya untuk gaji guru dan dosen.

\section{Latarbelakang liberalisasi Pendidikan}

Di negara-negara kapitalis besar, seperti AS, Kanada, Inggris, atau Australia, pendidikan merupakan penyangga peradaban mereka secara fundamental, sekaligus merupakan lahan industri strategis yang menjadi bagian dari dan berkontribusi pada pertumbuhan ekonomi negara bersangkutan. Di negara-negara itu, industri pendidikan tinggi tumbuh pesat seperti industri jasa dan perdagangan yang lain. Adalah Amerika Serikat di tahun 60-an, melakukan penelitian dan hasil penelitiannya menyimpulkan bahwa investasi dalam dunia pendidikan jauh lebih menguntungkan dibandingkan investasi di bidang saham. ${ }^{7}$ Dengan dana tidak kurang dari 6 milyar dolar, AS lalu membiayai penelitian terapan (applied research) dalam bidang pendidikan. Hasilnya adalah Amerika Serikat memiliki sebuah sistem pendidikan yang pragmatis dan berorientasi pasar, yang meniscayakan standarisasi semua bidang ilmu terhadap kebutuhan industri. Akhirnya mulai tahun 70-an hingga sekarang, Amerika Serikat menjadi kiblat pendidikan di dunia. ${ }^{8}$

Indonesia sendiri mulai mengikatkan diri dalam WTO sejak tahun 1994. Dengan diterbitkanya Undang-Undang No.7 Tahun 1994 tentang pengesahan (ratifikasi) —Agreement Establising the World Trade Organization”, maka Indonesia secara resmi telah menjadi anggota WTO dan semua persetujuan yang ada di dalamnya telah sah menjadi bagian dari legislasi nasional. Sebagai anggota WTO, Indonesia tentu saja tidak bisa menghindar dari berbagai perjanjian liberalisasi perdagangan, termasuk perdagangan jasa pendidikan. Kesepakatan ini dimotori oleh WTO, dimana pada tahun 2005 melalui General Agreement on Trade in Services (GATS) Indonesia sepakat untuk menandatangani kesepakatan tersebut. GATS mengatur liberalisasi

\footnotetext{
${ }^{7}$ Prof. Abuddin Nata, Pendidikan di Persimpangan Jalan, 2009

${ }^{8}$ Rum Rosyid, Perselingkuhan Dunia Pendidikan dan Kepentingan Kapitalis, 2010
} 
perdagangan sektor jasa pendidikan berdampingan dengan liberalisasi layanan kesehatan, teknologi informasi dan komunikasi, jasa akuntansi, serta jasa-jasa lainnya ${ }^{9}$.

Logika perdagangan jasa pendidikan, sebagaimana diutarakan oleh Rektor Universitas Gadjah Mada (UGM), Prof. Dr. Sofian Effendi mengikuti tipologi yang digunakan oleh para ekonom dalam membagi kegiatan usaha dalam masyarakat. Ilmu ekonomi membagi 3 sektor kegiatan usaha dalam masyarakat. Pertama adalah sektor Primer mencakup semua industri ekstraksi hasil pertambangan dan pertanian. Kedua, sektor sekunder mencakup industri untuk mengolah bahan dasar menjadi barang, bangunan, produk manufaktur dan utilities. Dan ketiga, sektor tersier yang mencakup industri-industri untuk mengubah wujud benda fisik (physical services), keadaan manusia (human services) dan benda simbolik (information and communication services). Sejalan dengan pandangan ilmu ekonomi tersebut, WTO menetapkan pendidikan sebagai salah satu industri sektor tersier, karena kgiatan pokoknya adalah mentransformasi orang yang tidak berpengetahuan dan orang yang tidak mempunyai keterampilan menjadi orang yang berpengetahuan dan mempunyai keterampilan ${ }^{10}$.

Kontribusi sektor tersier terhadap produk nasional suatu bangsa memang cenderung meningkat seiring dengan kemajuan pembangunan bangsa tersebut. Sejak 1980-an di negara-negara maju, perdagangan jasa tumbuh pesat dan telah memberikan sumbangan yang besar pada produk domestik bruto (PDB), lebih besar dibandingkan dengan sector primer dan sekunder. Tiga negara yang paling mendapaatkan keuntungan besar dari liberalisasi jasa pendidikan adalah Amerika Serikat, Inggeris dan Australia (Enders dan Fulton, Eds., 2002, hh 104-105). Pada 2000 ekspor jasa pendidikan Amerika mencapai US \$ 14 milyar atau Rp. 126 trilyun. Di Inggeris sumbangan pendapatan dari ekspor jasa pendidikan mencapai sekitar 4 persen dari peneimaan sector jasa negara tersebut. Menurut Millea (1998), sebuah publikasi rahasia berjudul Intelligent Exports mengungkapkan bahwa pada 1994 sector jasa telah menyumbangkan 70 persen pada PDB Australia, menyerap 80 persen tenaga kerja dan merupakan 20 persen dari ekpor total negara Kangguru tersebut, Sebuah survey yang diadakan pada 1993 menunjukkan bahwa industri jasa yang paling menonjol orientasi ekpornya adalah jasa komputasi, pendidikan dan pelatihan. Ekpor

9

Dani Setiawan, Liberalisasi Pendidikan danWTO.

10 Prof. Dr. Sofian Effendi, Strategi Menghadapi Liberalisasi Pendidikan Tinggi. 2005 
jasa pendidikan dan pelatihan tersebut telah menghasilkan AUS \$ 1,2 milyar pada 1993. Fakta tersebut dapat menjelaskan mengapa tiga negara maju tersebut amat getol menuntut liberalisasi sektor jasa pendidikan melalui WTO ${ }^{11}$.

Inilah pangkal masalah mahalnya biaya pendidikan itu. Yaitu negara ini menggunakan paradigma kapitalisme dalam mengurusi kepentingan dan urusan rakyat termasuk pendidikan. Ideologi Kapitalisme memandang bahwa pengurusan rakyat oleh Pemerintah berbasis pada sistem pasar (market based system). Artinya, Pemerintah hanya menjamin berjalannya sistem pasar itu, bukan menjamin terpenuhinya kebutuhan masyarakat. Dalam pendidikan, Pemerintah hanya menjamin ketersediaan sekolah/PT bagi masyarakat; tidak peduli apakah biaya pendidikannya terjangkau atau tidak oleh masyarakat. Pemerintah akan memberikan izin kepada siapa pun untuk mendirikan sekolah/PT termasuk para investor asing. Anggota masyarakat yang mampu dapat memilih sekolah berkualitas dengan biaya mahal. Yang kurang mampu bisa memilih sekolah yang lebih murah dengan kualitas yang lebih rendah. Yang tidak mampu dipersilakan untuk tidak bersekolah.

Jelas, kekhawatiran masyarakat mengenai kian mengentalnya paham neoliberalisme dalam penyelenggaraan pendidikan tinggi bukan tanpa alasan. Bahkan pemikir-pemikir pendidikan di Amerika-negara asal kelahiran mazhab neoli-beralisme-sekalipun juga risau atas praktik pendidikan tinggi yang berazas pada ideologi kapitalisme pasar bebas yang menjelma dalam mazhab neoliberalisme itu. Seorang pemikir critical pedagogy, Henry Giroux, menyebut neoliberalisme telah meneror ruang-ruang publik ketika lembaga pendidikan tinggi berpraktik menyerupai korporasi yang bersifat dominatif, eksploitatif, dan hegemonik.

Proyek komersialisasi sekolah yang sedang berjalan sekarang sangat mungkin mencerminkan kesulitan, bahkan kegagalan pendidikan dalam melepaskan diri dari jerat kapitalisasi. Jerat kapitalisasi pendidikan, menurut Darmaningtyas (2005), menjadikan pendidikan harus 'menyembah' kepada aturan main pasar, sehingga kebijakan dunia pendidikan bukan lagi berorientasi kepada pencerdasan dan pemanusiaan manusia, tetapi justru menjadi ajang mengeruk keuntungan finansial.

11 idem 
bila sekadar terobsesi oleh motif ekonomi semata, perguruan tinggi akan cenderung mengabaikan fungsi utama sebagai lembaga produsen ilmu pengetahuan, pelopor inovasi teknologi, serta pusat eksperimentasi dan observatorium bagi penemuan-penemuan baru.

Skema pembiayaan pendidikan gratis

Pada tahun 2007 terdapat kesepakatan antara Pemerintah dan DPR tentang dana anggaran untuk sektor pendidikan hanya sebesar Rp. 51,3 trilyun (hanya 10,3 \% dari total APBN), angka itu sedikit naik dari tahun 2006 yang sebesar Rp. 36,7 trilyun (9,1 \% dari total APBN). Sepanjang tahun 2006 s/d 2009 alokasi anggaran pendidikan sebesar 210 trilyun, dimana angka tersebut jauh lebih sedikit dibanding beban pembayaran utang luar negri. Alokasi pembayaran bunga utang dalam negri sebesar Rp. 38,84 trilyun, bunga utang luar negri Rp. 25,14 trilyun, cicilan pokok utang luar negri sebesar Rp. 46,84 trilyun. Jika ditotal, maka pembayaran utang luar negri telah menghabiskan $25,10 \%$ dari total belanja negara yang berjumlah Rp. 441,61 trilyun, yang berarti juga memboroskan pendapatan negara sebesar 29,33\%.

Indonesia memiliki potensi besar untuk bisa memberikan kesejahteraan bagi masyarakat, dengan melihat letak geografis Indonesia sangat menguntungkan, karena kita memiliki kekayaan alam yang luar biasa kaya. Lihat saja pendapatan dari berbagai industri pertambangan asing di Indonesia seperti Exxon Mobil pada tahun 2007 berdasarkan laporannya, yang mencapai angka \$ 40,6 Billion atau Rp3.723 trilyun serta Chevron ditahun 2007 mampu memperoleh keuntungan sampai \$ 18,7 Billion atau Rp 171 trilliyun. Demikian pula dengan 137 pertambangan asing lainnya di Indonesia yang juga mengeruk keuntungan di negri berlahan subur ini. Bandingkan dengan keuntungan pemerintah dari hasil tambang yang telah dijual ke asing, tidak pernah menembus angka 3\%. Tidak seharusnya negeri ini miskin, karena sama sekali tidak memiliki alasan untuk itu.

\section{Penutup}

Bangsa yang besar adalah bangsa yang memprogram seluruh elemen internal sebagai kekuatan untuk membangun negara. Sumber daya manusia adalah salah satu dari elemen tersebut, dan tentu saja manajemen sumber daya manusia merupakan sesuatu yang paling penting. Tentu kita bisa bayangkan bagaimana sebuah bangsa bisa membangun sedangkan generasinya bukanlah 
generasi yang siap untuk membangun, bahkan lebih ironis jika generasinya bukanlah generasi pembangun namun hanya sebagai generasi penikmat pembangunan.

Pendidikan merupakan kebutuhan publik yang seharusnya setiap warga masyarakat memiliki akses terbuka untuk bisa mengenyam pendidikan, bahkan dengan paradigma yang tepat yaitu untuk membangun bangsa maka sudah sewajarnya pemerintah memberikan kemudahan untuk masyarakatnya mendapat akses pendidikan bahkan bukan tidak mungkin Indonesia bisa menyelenggarakan pendidikan gratis dalam semua jenjang, karena sebenarnya pendidikan merupakan investasi untuk membangun negara dengan sumber daya yang handal, kredibel dan berintegrasi.

\section{Daftar Pustaka}

Enders, Jurgen dan Oliver Fulton. Eds., Higher Education in a Globalizing World.Dordrecht. luwer Academic Publishers. 2002.

Prof. Dr. Sofian Effendi Strategi Menghadapi Liberalisasi Pendidikan Tinggi.Makalah disampaikan pada Seminar Nasional —Pendidikan Tinggi di Era Pasar Bebas:
Tantangan, Peluang dan Harapanll, diselenggarakan oleh Universitas Islam Negeri Syarif Hidayatullah dan Universitas Katolik Atma Jaya, Jakarta, 2 Mei 2005.

Drs. Rum rosyid, MM.Perselingkuhan Dunia Pendidikan Dan Kepentingan Kapitalis. Universitas Tanjungpura Pontianak. 2010. 